\title{
Options Pricing by Monte Carlo Simulation, Binomial Tree and BMS Model: a comparative study of Nifty50 options index
}

\author{
Ali Bendob ${ }^{1}$ \\ Institute of economic sciences, management, and commercial sciences, \\ LMELSPM Laboratory at university center of Ain Temouchent, Algeria. \\ bendobali4@gmail.com \\ Naima Bentouir \\ Institute of economic sciences, management, and commercial sciences, \\ LMELSPM Laboratory at university center of Ain Temouchent, Algeria. \\ naima.bentouir4@gmail.com
}

\begin{abstract}
Investment behaviour, techniques and choices have evolved in the options markets since the launch of options trading in 1973. Today, we are entering the field of Big Data and the explosion of information, which has become the main feature of science, impacts investors' decisions and their trading position, particularly in the financial markets. Our paper aims to testing the effectiveness of the most popular options pricing models, which are the Monte Carlo simulation method, the Binomial model, and the benchmark model; the Black-Scholes model, when we ignore/take on account the Moneyness categories and different time to maturities; five months, one year, and two years, in addition to comparing these models, we will then test the effect of each model on the prediction of the current options prices, using the regression analysis, and the Nifty50 option index during the period of 25/07/2014 to 30/06/2016. The result shows that all models are overpriced in all Moneyness categories with a high level of volatility in In-the money category, other finding concludes that the Monte Carlo Simulation method is outperforming when the volatility is lower, while the Black-Sholes model and the Binomial model are outperforming in the entire sample with ignoring the Moneyness.
\end{abstract}

JEL classification: C13, C15, G12, G13, G15, G17.

Key words: options pricing, option markets, Black-Scholes model, Binomial model, Monte-Carlo Simulation model, Greek letters.

\section{INTRODUCTION}

The rapidly growth of the financial innovations such as financial engineering instruments, made the dealing on the forward markets more complexity and risky. The trading volume of financial derivatives has been augmenting more and more than the total economic output of the entire world; although the riskiness of this tools. Derivatives contracts exist on several of financial

Corresponding author. Institute of Economics, Commerce and Management Sciences, University (Centre) of Ain Temouchent BP 284, Ain Témouchent 46000 - Algeria. 
underlying asset like stocks, interest rates, etc. It exists also as commodities such as gold, silver, oil, etc. so risk sharing and risk management are increasingly being viewed as a main provenance of value creation in markets.

The options one of the main contracts on financial derivatives, which mean a contract between two parties (seller and buyer), it gives the holder the right, not the obligation to buy (call option) or sell (put option) the underlying asset at a specified date. Options markets have been growing fastly since the seventies 1973's year when the economists Black Fisher and Myron Sholes presented a formula for pricing European options type, this formula has been a benchmark model, and it is widely applied in many types of researches, although the many criticisms on this model. In 2016 , options accounted for $38 \%$ of the total volumes traded and futures, $62 \%$. This is a change in 2015 , when options accounted for $42 \%$ of global volumes traded. Overall, options volumes fell by $8 \%$, while the number of futures contracts traded increased by $10 \%$ in 2015 (www, statista. com). This type of contracts has been taking a large part of investigations in the academic world, because of their complex characteristics and degree of risk. Buildings on that many researchers and economists have developed several models in order to pricing options and try to present the perfect pricing model which is evidentially an important theme in the mathematical finance literature and financial industry.

Options trading history back to the seventeenth century, several economist and mathematicians worked on creating a theory of rational options pricing. In 1900 the French Louis Bachelier presented his model which was based on the assumption that the stock prices flow a Brownian motion. In 1973 the Chicago Board Exchange of Options (CBOE) raised when the trading of option contracts has begun on standardized listed options. In the same year, the economists Black Ficher and Merton Scholes proposed a formula for evaluating European option type most popular and fundamental model in mathematical finance is the

Black-Scholes model Miyahara (2012), under may assumptions such as the stock prices follow the geometric Brownian motion; the Constance of the variance as well as the risk-free rate. Over the time the options markets became too complex and characterized by the high volatile on option contracts trading; when the Black-Scholes model is not fully adapted with these fluctuations and exigencies of markets with the unrealistic assumptions of the Constance of volatilityRoman (2004). So a great number of new models have presented after the Black-Scholes model, such as the Cox-Ross-Rubinstein is also known as the binomial model is fully developed and illustrated with both the Monte Carlo method and with pricing trees. Katz and McCO RMI (2005).

The complexity and high degree of riskiness are the main characteristics of options, which led to the development of a variety of option pricing models by the academia and the economists; researchers have developed many models that taking time on consideration, they are namely the continuous time models; such as the stochastic volatility model, realized volatility and GARCH models. The models have been successful in option markets because of the ability to forecasting future volatility; but they can be arduously to implement, because it is very difficult to filter a continuous volatility variable from discrete; these models proved them successful in both markets developing and emerging, which are associated and integrated in the last few years given to requirements of the globalization.

The objective of the current paper is to choose the best model on predicting option prices by making a comparison between three different models; Black-Scholes, Carlo Simulation method which presents the continuous time models Binomial and Monte, which presents the discrete time model, depending on many previous studies which presented a large investigations about the outperform models on options pricing, building on that we are going to use the most important models proposed on the pricing option framework. The rest of this paper is organized as follows: section 2 represent some literature review, section three describe the sample data and the methodology, section four and five introduce the main results and discussion respectively finally, the main conclusion will be present in the sixth section. 


\section{LITERATURE REVIEW}

Financial option contracts have widely used in the field of finance since 1973 when the benchmark model was presented by Black-Sholes in order to evaluate these contracts which have been the topic of active research. Many researchers examined the various type of mathematical model for pricing different types of options. In this section, we will discuss some past studies which have been investigating on our subject. The study of Bentouir et al (2018) aimed to compare two options pricing models which are the Monte Carlo Simulation method and the Black-Sholes model, using call stock options in Kuwait stock exchange, covering the period of 26/12/2013 to $08 / 05 / 2014$, with daily data; the main results of this empirical study showed that the Black-Scholes model is outperforming when the volatility is lower; with a positive relationship of prediction the current prices for one year of maturity. Other finding highlighted the validity of Monte Carlo Simulation method to predict the current prices in six and nine months. The investigation of Robentrost et al. (2018), presented a quantum computational finance Monte Carlo pricing of financial derivatives, under many assumptions like the random distribution of the underlying, and the efficiency of the derivative payoff function. This paper showed the possibility of prepared the relevant probabilities in quantum superposition, furthermore, the authors gave a brief summary about B-S Merton options pricing, a classical Monte Carlo estimation, and discussed the European call option and the Asian option which depend on the average asset price before the maturity date. Srivastava and Shastri (2018) investigated on the relevance between the theoretical price under the B-S model and the market price, using a sample of seven stock of companies over the period of $01 / 01 / 2017$ and 25/01/2017 and the paired simple T test, the main result of this study showed the stocks with lower prices are more consistent because of the lower premium for these options and show a lower volatility, other finding concluded that there is a significant difference between the market price and the value given by the B-S model. Jying et J. e. al (2017), tried in theme study to forecasting Taiwanese stock index option prices: the role of implied volatility index, Taiwan Weighted Stock Index (TAIEX) for a total of 839 trading days from 2 January 2012 to 29 May 2015, using GARCH, GARCHvix and the historical volatility models, they concluded that, both GARCH and GARCHvix models perform better than the historical volatility models for forecasting call value of TXO additionally, the GARCHvix model outperform than GARCH model; furthermore, GARCH model can be effectively improved with the additional information contained in VIX, and the usage of GARCHvix can greatly reduce model mispricing for TXO value, finally Volatility index is important for option traders to efficiently predict TXO option value with GARCH model. While the study of Xia (2017), investigated on pricing exotic power options with a Brownian-time-changed variance gamma process, using S\&P500 index over the period of 2 July 2015 to 1 July 2016 with a total number of 253 observations and Browniantime changed variance gamma model the result showed that pricing for plain-vanilla options is considerably efficient, and an asymmetric power options can be regarded as a plain-vanilla option a new powered price stock and follows the same pricing mechanism, other finding showed that Symmetric power options can be priced in two approaches, with infinite series expansion and the other with some advanced functional, finally, the estimator of the log stock price at a fixed time point is asymptotically unbiased, and pricing through simulations readily available. Using Fractional Black-Scholes and Li\&Chen models Flint and Maré (2017), focused on the Fractional B-S Option Pricing, Volatility Calibration and Implied Hurst Exponents in South African Context with 529 weekly observations of IV skews for listed Futures options on the FTSE/JSE Top40 Index over the period of 2005-2015, and 146 weekly observations of IV skews for listed futures options on (USD/ZAR) exchange rate during 2013-2015. This investigation concluded that FBSI model fits the equity implied volatility very well, and the decomposition of IV into long memory and fractional volatility components provides one with more detailed information on the true uncertainty in the underlying asset price process; thus, The calibrated 
FBSI volatility surface still manages to capture most of the traded surfaces characteristics with the added benefit of being fully analytic; an important consideration when valuing exotic derivatives under local volatility. Swishchuk and Shahmoradi (2016), which untitled by pricing crude oil options using levy processes European style crude oil futures options in NYMEX index during 2015 to 2016 under the Normal Gaussian Process, Jump Diffusion Process, Variance-Gamma Process. This examination deduced the crude oil prices Show significant jumps that are very frequent, also, crude oil price returns show skew as well, in addition, in the case of JDM, the volatility of size of the -jumps is bigger than volatility of the diffusion part other finding showed, the VG process results in slightly smaller volatility than JDM as well as the mean of the jump component size implied by JDM, and skew parameter of VG process both indicate existence of right-skew in crude oil price returns but the NG process implies that the density of returns are skewed to the left. Čirjevskisa and Tatevosjans (2015), tested the real option in the real Estate market, in order to analysis of investment project "Sun village", during the period of 2008 to 2013 using three real option valuations methods; Tomato Garden, Black-Sholes and Binomial option pricing models, the main results which were founded by the authors are; the option to sell current project is inefficient, and the existence of the uncertainty concerning the project outcome due to high volatility level, finally both of the Black-Sholes and the Binomial model proves their efficiency to predict approximately the same result of option value. The study of Girish and Rastogi (2013), examined the efficiency of the European call/put S\&P CNX Nifty index options during the period of 1/1/2002 to 31/12/2005 using high-frequency data and Box-spread strategy, the findings highlighted that the internal option market is efficient over the years for the S\&P CNX Nifty index option. Black and Scholes (1973); presented a paper untitled by the pricing of options and corporate liabilities, under the principle of the options are not correctly priced in the markets. They developed a theoretical valuation formula for European call/put options that can be executed only on the expiry date, the formula given under the assumption of the ideal conditions in the market, so the value of the option depending on the stock price and the option life, and the variables that are taken to be know and constant as well as the volatility and the risk-free rate. Cox et al. (1979), presented a simple discrete time model for the valuing options; they took on account the principle of option pricing by arbitrage method, this approach gave some assumptions, which are the stock prices follow a multiplicative binomial process, the rate of return on the stock can be upward or downward, thus the absence of the taxes and the transaction costs. This approach concluded that the options can be priced solely on that basis of arbitrage considerations.

Our sample of previous studies tried range between the fundamental papers which gave a different model and mathematical formulas on options pricing, and investigations which tried to find the outperform models under different samples and periods since the creation of the benchmark model (Black-Scholes), till this day the researchers couldn't identify the models which can be used in all of options markets or give a lower level of mispricing, because of the substantial differences of these markets and investors behavior, in addition to other crucial factors which have a big influence.

\section{DATA AND METHODOLOGY}

The present paper is based on secondary data that is collected from the IVolatility.com, and the National Stock Exchange of India websites, our data consists the European call options data under the Nifty50 index during the period of 25/07/2014 to 30/06/2016, with 463 contracts, the historical prices were collected from the Finance yahoo website, such as the risk free rate that is obtained from the federal reserve bank. 
We divided our data into two categories; the first one by the Moneyness (In the Money (ITM), At the money (ATM) and Out of the money (OTM)) and into times to maturities (5 months, one year, and 2 years).

Where the moneyness range between the following interval (ITM, ATM, OTM) respectively:

$$
\begin{aligned}
& 1.2 \leq M<1.9 \\
& 0.9 \leq M<1.2 \\
& 0.8 \leq M<0.9
\end{aligned}
$$

Moneyness "M" defined by:

$$
M=\frac{S}{K}
$$

We also use the Ordinary Least Square (OLS) regression to examine the relationship between the current price and the theoretical prices.

$$
C(s, t)=\alpha_{0}+C_{T p}+\varepsilon_{t}
$$

Where: $C(s, t)$ is the option current price, and $C_{T p}$ are the theoretical prices

\subsection{The mathematical models}

\subsubsection{The Black-Sholes model}

The geometric Brownian motion model or the Black-Sholes model, it is the benchmark model in options pricing model, which presented in the early 1970s when Fisher Black, Myron Sholes and Merton achieved a major model in the pricing of European stock options Hull (2015), under many assumptions as follow:

- The risk-free rate is known and constant, as well as the variance rate;

- The stock price follows a random walk in continuous time;

- The log-Normal distribution of the stock prices;

- The absence of the dividends or other distributions;

- The option is European;

- There are no transaction costs;

- There are no penalties to short selling.

\section{The Black-Scholes formula}

The Black-Sholes formula was given as follows:

We start by the differential equation formula for the value of the option;

$$
w_{2}=r w-r x w_{1}-0.5 v^{2} x^{2} x_{11}
$$

With the " $t$ ", is the maturity date and $\mathrm{c}$ is the strike price and $x$ is the spot price we can right this next formula:

$$
\begin{array}{ll}
w\left(x, t^{*}\right)=x-c, & x \geq c \\
=0, & x \prec c
\end{array}
$$


To solve the differential the following illustration was given as follow:

$w(x, t)=e^{r\left(t-t^{*}\right)}\left[\left(2 / v^{2}\right)\left(r-0.5 v^{2}\right)\left[\ln x / c-\left(r-0.5 v^{2}\right)\left(t-t^{*}\right)\right],-2 / v^{2}\left(r-0.5 v^{2}\right)^{2}\left(t-t^{*}\right)\right]$

Where: $v^{2}$ is the variance, $\left(t-t^{*}\right)$ is the time to maturity.

After that the differential equation becomes:

$$
y_{2}=y_{11}
$$

This equation is the heat-transfer equation of physics, and it solution was given as follow:

$$
y(u, s)=1 / \sqrt{2 \pi} \int_{-u / \sqrt{2 s}}^{\infty} c\left[e^{(u+q \sqrt{2 s})\left(0.5 v^{2}\right) /\left(r-0.5^{2}\right)}-1\right] e^{-q^{2} / 2} d q
$$

From the equations (3) and (5) the option value formula becomes:

$$
w(x ; t)=x N\left(d_{1}\right)-c e^{r\left(t-t^{*}\right)} N\left(d_{2}\right)
$$

Where: $w(x ; t)$ is the theoretical price of option.

$$
\begin{aligned}
& d_{1}=\frac{\ln x / c+\left(r+0.5 v^{2}\right)\left(t^{*}-t\right)}{\sigma \sqrt{\left(t^{*}-t\right)}} \\
& d_{2}=\frac{\ln x / c+\left(r-0.5 v^{2}\right)\left(t^{*}-t\right)}{\sigma \sqrt{\left(t^{*}-t\right)}}
\end{aligned}
$$

or $d_{2}=d_{1}-\sigma * \sqrt{T}$ Ser-Huang and Stapleton (2005)

Where: " $w$ " is the option price, " $x$ " is the spot price, " $c$ " the strike price, $t$ " is the maturity time, $N(d)$ is the cumulative normal density function. Black and Scholes (1973)

\subsubsection{The Binomial model}

Cox, Ross and Rubinstein presented a simple discrete time option pricing formula in 1979, where the fundamental economic principles of option pricing using arbitrage method are shown in this work. This approach includes the Black-Scholes model as a special limiting case, by taking the limits in a different way, wherein, the economic arguments used in the CRR model about the relationship between the value of the options and the stock price is precisely the same as those advanced by B-S in 1973 .

\section{Assumptions of the model}

a - The stocks prices follow a multiplicative binomial process over the discreet period;

$\mathrm{b}-$ The rate of return on the stock have two cases; $u-1$ with probability $q$, or $d-1$ with probability $P$;

c - Stock prices at the end of the period will be up or down;

d - The interest rate constant;

e - There are no taxes or transaction costs or margin requirements. 


\section{The Binomial pricing options formula}

Presentation of the simplest situation of the call option:

$$
c\left[\begin{array}{l}
c_{u}=\operatorname{Max}[0 ; S u-K] q \\
c_{d}=\operatorname{Max}[0 ; S d-K] p
\end{array}\right.
$$

This simple presentation shows the movement of the option value depending on the changes in the stock prices.

Supposing that there is a portfolio includes $\Delta$ shares of stock and $\mathrm{B}$ is the amount in riskless bonds, we get this situation:

$$
\Delta s+B\left[\begin{array}{l}
\Delta u S+r B-\frac{\text { with }}{{ }^{2}} \longrightarrow p \\
\Delta d S+r B-\frac{\text { with }}{\longrightarrow} q
\end{array}\right.
$$

We can get:

$$
\begin{aligned}
& \Delta u S+r B=C u \\
& \Delta d S+r B=C d
\end{aligned}
$$

Solving this equation; finding the hedging portfolio;

$$
\begin{gathered}
\Delta=\frac{C u-C d}{(u-d) S} \\
B=\frac{u C d-d C u}{(u-d) r}
\end{gathered}
$$

From this entire, if there are no riskless arbitrage opportunities, we can write this equation:

$$
c=\Delta S+B=\frac{C u-C d}{u-d}+\frac{u C d-d C u}{(u-d) r}=\left[\left(\frac{r-d}{u-d}\right) C u+\left(\frac{u-r}{u-d}\right) C d\right] / r
$$

This equation can be simplified by the following formula: Jhon et al. (1979)

$$
C=[p C u+(1-p) C d] / r
$$

Where:

$$
p=\frac{r-d}{u-d} \text { and, } 1-p=\frac{u-r}{u-d}
$$

$\mathrm{P}$ is the probability of the option price movements (up or down).

\subsubsection{The Monte Carlo simulation method}

Monte Carlo simulation (MCS) has a long history in sciences such as physical science, when it used to estimate the expected value of a random variable, and it also used in other sciences for solving analytically intractable integral calculus problems, as well as it used in finance field in order to solve pricing problems, through the determination of the expected value of function of one or many underlying securities. 


\section{Options pricing by Monte Carlo Simulation}

Monte Carlo Simulation method can be applied for the European option, but can't apply for the American option style; wherein we can simulate possible paths for a stock price over the life of option from " $t$ " to " $T$ ".

\section{Generating the stock price using Monte Carlo Simulation}

The stock price in this method follows approximately a Geometric Brownian Motion, random walk, the equation below represents the generation of the stock price:

$$
S_{\left(t_{J}+1\right)}=S_{\left(t_{J}\right)} * e^{\left[\left(r-0.5 \sigma^{2}\right) * \sqrt{\Delta}+\sigma * \sqrt{\Delta} \epsilon_{J}+1\right]}
$$

Where: $S_{\left(t_{J}\right)}$ is the initial stock price, and $\in_{J}+1$ is the $\operatorname{IIDN}(0,1)$.

The simulation of the option value based on the present value of the average of payoff:

$$
\begin{array}{ll}
\text { For call option } & \text { Max }=\left[S \_K ; 0\right] \\
\text { For put option } & \operatorname{Max}=\left[K \_S ; 0\right]
\end{array}
$$

$S$ is the spot price and $K$ is the strike price.

The present value is given by the following formula: Crack (2009)

$$
P V=\text { Average } * e^{-r * t}
$$

Graph 1 shows the simulation of the stock price of a call option depending on time to maturity.

Graph 1.

Simulation of stock prices using Monte Carlo Simulation

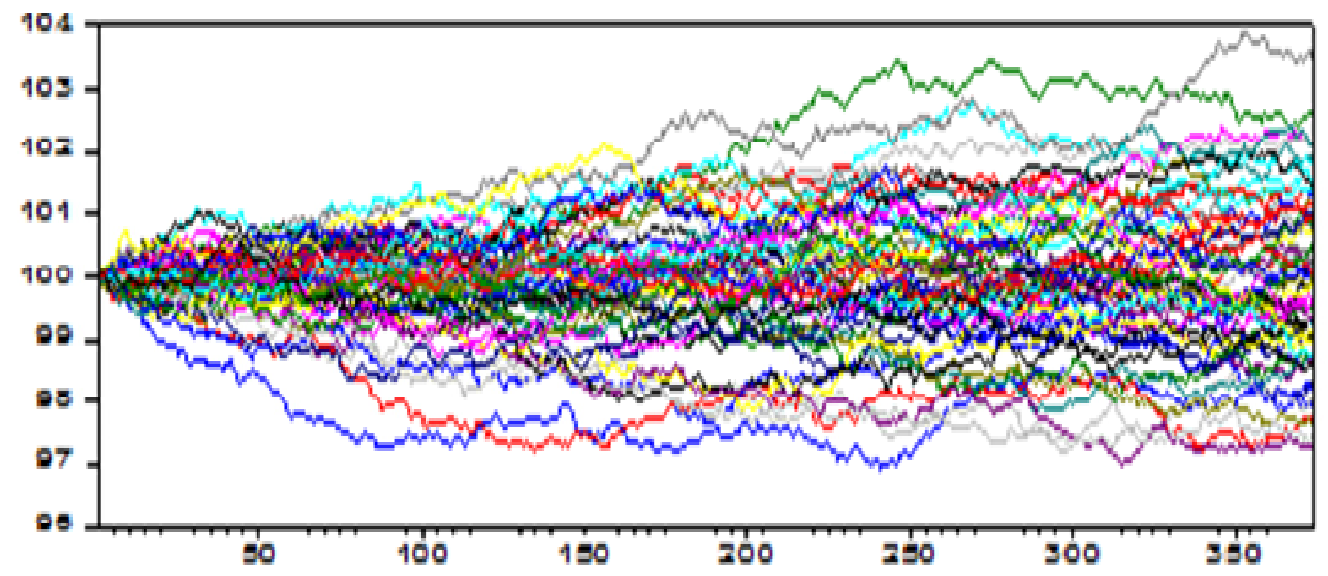

Sources: Authors.

\section{RESULTS}

In order to understand and know the characteristics of our data and the outputs of all models, we will show the descriptive statistics of each category and each period.

Table 1 shows the descriptive statistics of the current and theoretical prices of call options and their characteristics, in three different categories of Moneyness. The standard deviation indicates a higher fluctuation in their prices in In-the money category than the other categories, while the Black-Sholes prices show high volatility comparatively by the Monte Carlo Simulation and the Binomial model prices respectively. A small deviation has appeared in the category of 
At-the money from the mean value, when the Monte Carlo Simulation prices have a lower fluctuation comparatively by the current prices, followed by the Black-Sholes and the Binomial model respectively. The third category Out-of the money appears a lower variation from their mean, the Monte Carlo Simulation prices compared to the B-S and the CRR respectively. The Skewness is positive and different to zero that indicates a right tail and non-normal distribution of prices, which confirmed by the Kurtosis that is different to 3 .

Table 1.

Descriptive Statistics of Market Price and Theoretical Prices of Option

\begin{tabular}{|c|c|c|c|c|}
\hline & Mean & Std. Dev & skewess & kurtosis \\
\hline \multicolumn{5}{|c|}{ In the money } \\
\hline Current prices & 773.6049 & 1303.590 & 1.526940 & 4.256135 \\
\hline B-S prices & 3176.204 & 1086.576 & 0.243180 & 1.987604 \\
\hline CRR prices & 3130.269 & 1145.297 & 0.317479 & 2.157465 \\
\hline MCS prices & 2993.505 & 1092.879 & 0.292912 & 1.946116 \\
\hline \multicolumn{5}{|c|}{ At the money } \\
\hline Current prices & 292.7176 & 428.4764 & 1.350441 & 3.759105 \\
\hline B-S prices & 826.5163 & 502.2075 & 0.313788 & 2.373334 \\
\hline CRR prices & 631.4867 & 639.3497 & 0.080637 & 2.530264 \\
\hline MCS prices & 561.7042 & 494.5747 & 0.451466 & 2.051019 \\
\hline \multicolumn{5}{|c|}{ Out of the money } \\
\hline Current prices & 8.464407 & 24.16100 & 3.798360 & 17.92294 \\
\hline B-S prices & 123.1321 & 157.8379 & 1.638303 & 5.285195 \\
\hline CRR prices & -929.4692 & 508.1874 & 0.069445 & 2.384516 \\
\hline MCS prices & 6.537937 & 31.54199 & 6.390141 & 49.32185 \\
\hline
\end{tabular}

Source: Authors

The Graph 2 shows the changes of the call options depending on the spot price during option life.

\section{Graph 2.}

The sensibility of the call options to the stock prices
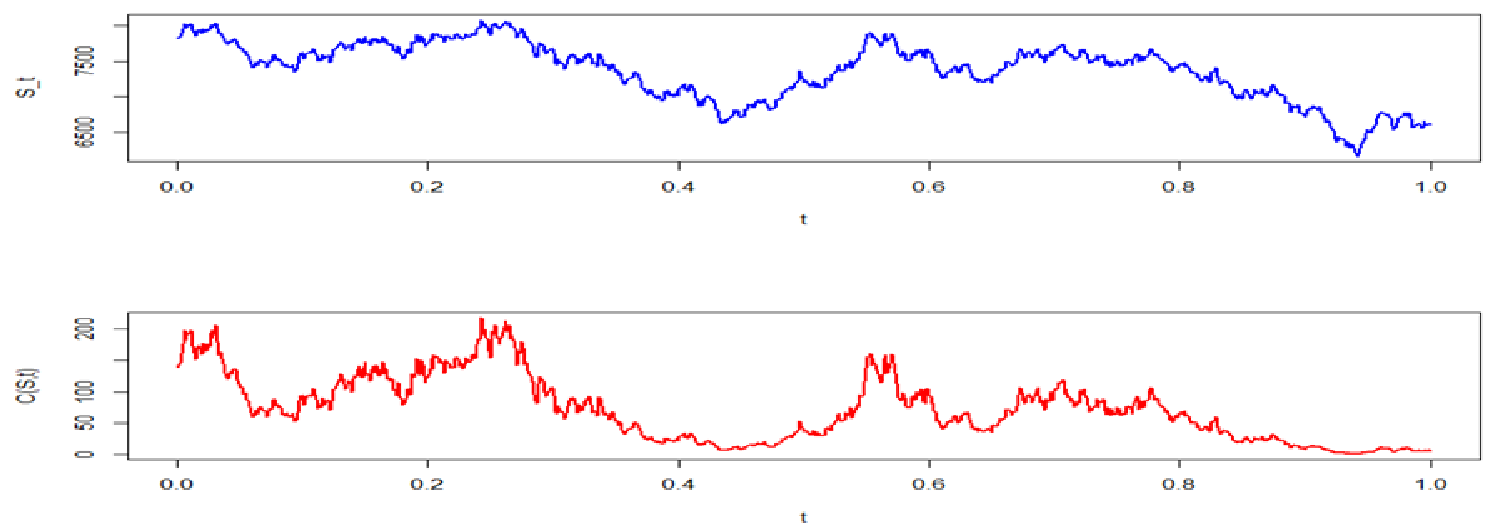

Source: Authors. 
Table 2 presents the estimation of the current price of call options on the theoretical prices in the case of In-The money.

Table 2.

Regression results of the relationship between current price of call options on the theoretical prices (ITM)

\begin{tabular}{lcccc}
\hline \hline & Coefficient & S.d.v & T. statistic & P. value \\
\hline Constant & 809.0117 & 268.6611 & 3.011272 & 0.0030 \\
B-S & 1.880985 & 0.693708 & 2.711495 & 0.0073 \\
CRR & -3.696228 & 0.481602 & -7.674862 & 0.0000 \\
MCS & 1.857484 & 0.418042 & 4.443291 & 0.0000 \\
\hline R-Squared & 0.334670 & F. Statistic & 30.68386 & 0.000000 \\
Adj-R & 0.323763 & P. Value & & \\
\hline
\end{tabular}

Source: Authors

The table 2 shows the relationship between the current price and the theoretical prices under three different categories In-the money (ITM), At-the money (ATM), Out-of the money (OTM), we used the Least Ordinary Square (OLS), Regression Analysis in order to examine the effect of each model (Black-Sholes, Binomial and the Monte Carlo Simulation method) on the current price, after the estimation the result appears that the theoretical prices of three different models in the case of In-the money have a significance at 1\%,5\%,10\% level, to predicting the current prices, while the coefficient of the B-S and the Monte Carlo Simulation models have a positive relationship with the current price except for the Binomial model which have a negative relationship; the R-square and Adjusted-R are near to 0.33 that means $33 \%$ of the prediction of the current prices can be explained by the theoretical prices, and $77 \%$ of the variation explained to other factors, the hole model was accepted depending to Fisher probability.

Table 3 shows the estimation of the current price of call options on the theoretical prices in the case of At-The money.

Table 3.

Regression results of the relationship between current price of call option on the theoretical prices (ATM)

\begin{tabular}{|c|c|c|c|c|}
\hline & coefficient & Std. Dev & T. statistic & P. value \\
\hline constant & 452.5450 & 89.75094 & 5.042232 & 0.0000 \\
\hline B-S & -1.134002 & 0.234547 & -4.834865 & 0.0000 \\
\hline CRR & 0.235757 & 0.206171 & 1.143503 & 0.2546 \\
\hline MCS & 1.119034 & 0.131451 & 8.512964 & 0.0000 \\
\hline R-Squared & 0.416461 & F. S & \multicolumn{2}{|c|}{36.87354} \\
\hline Adj-R & 0.405167 & P. V & \multicolumn{2}{|c|}{0.000000} \\
\hline
\end{tabular}

Source: Authors.

Table 3 reveals the effect of the theoretical prices on the current prices in At-the money category, the result indicates that the theoretical prices of B-S and MCS models have a significance at $1 \%, 5 \%, 10 \%$ level, to predict the current prices, except the Binomial model the coefficient of the B-S model has a negative relationship with the current prices, while the coefficient of MCS method has a positive relationship; the R-square and Adjusted-R are near to 0.42 that means $42 \%$ 
of the prediction of the current prices can be explained by the theoretical prices, and $58 \%$ of the variation explained to other factors, the hole model was accepted depending to Fisher probability.

Table 4 highlights the estimation of the current price of call options on the theoretical prices in the case of Out-of-The money.

Table 4.

Regression results of the relationship between current price of call option on the theoretical prices (OTM)

\begin{tabular}{|c|c|c|c|c|}
\hline & coefficient & Std. Dev & T. statistic & P. value \\
\hline constant & 35.66629 & 6.200938 & 5.751757 & 0.0000 \\
\hline B-S & -0.026483 & 0.018586 & -1.424908 & 0.1569 \\
\hline CRR & 0.025016 & 0.004870 & 5.136388 & 0.0000 \\
\hline MCS & -0.105504 & 0.082835 & -1.273659 & 0.2054 \\
\hline R-Squared & 0.195511 & F. Statistic & & \\
\hline Adj-R & 0.174340 & P. Value & & \\
\hline
\end{tabular}

Source: Authors.

Table 4 presents the effect of the theoretical prices on the current prices in Out-of-the money category, the result highlights that the theoretical prices of B-S and MCS models don't significant at 1\%,5\%,10\% level of significance, and have a negative relationship depending on the coefficient, except the Binomial model which has a positive relationship and a significant at $1 \%, 5 \%, 10 \%$; the R-square and Adjusted-R are near to 0.18 that means $18 \%$ of the prediction of the current prices can be explained by the theoretical prices, and $82 \%$ of the fluctuation explained to other determinants, the model was accepted depending to Fisher probability.

In table 5 we will show the estimation of the current price of call options on the theoretical prices by ignoring the Moneyness.

Table 5.

Regression results of the relationship between current price of call option on the theoretical prices ignoring the moneyness

\begin{tabular}{lcccc}
\hline \hline & coefficient & Std. Dev & T. statistic & P. value \\
\hline constant & 514.5884 & 101.6758 & 5.061071 & 0.0000 \\
B-S & -1.366015 & 0.254555 & -5.366283 & 0.0000 \\
CRR & 1.341658 & 0.199614 & 6.721278 & 0.0000 \\
MCS & 0.160767 & 0.103631 & 1.551333 & 0.1215 \\
\hline R-Squared & 0.150023 & F. Statistic & 27.00491 \\
Adj-R & 0.144468 & P. Value & 0.000000 \\
\hline \hline
\end{tabular}

Source: Authors

The table 5 widens the significance of the B-S and the Binomial model at 1\%, 5\%,10\% level of significance the coefficient reveals to the negative/positive relationship with B-S model and the CRR models respectively, except the MCS method, which doesn't significant; the R-square and Adjusted-R are lower than the other category with 0.15 that means just $15 \%$ of the prediction of the current prices can be explained by the theoretical prices, and $85 \%$ of the variation explained to other factors, the model was accepted depending to Ficher probability. 


\section{Graph 3.}

The convergence between the current price and the theoretical prices.

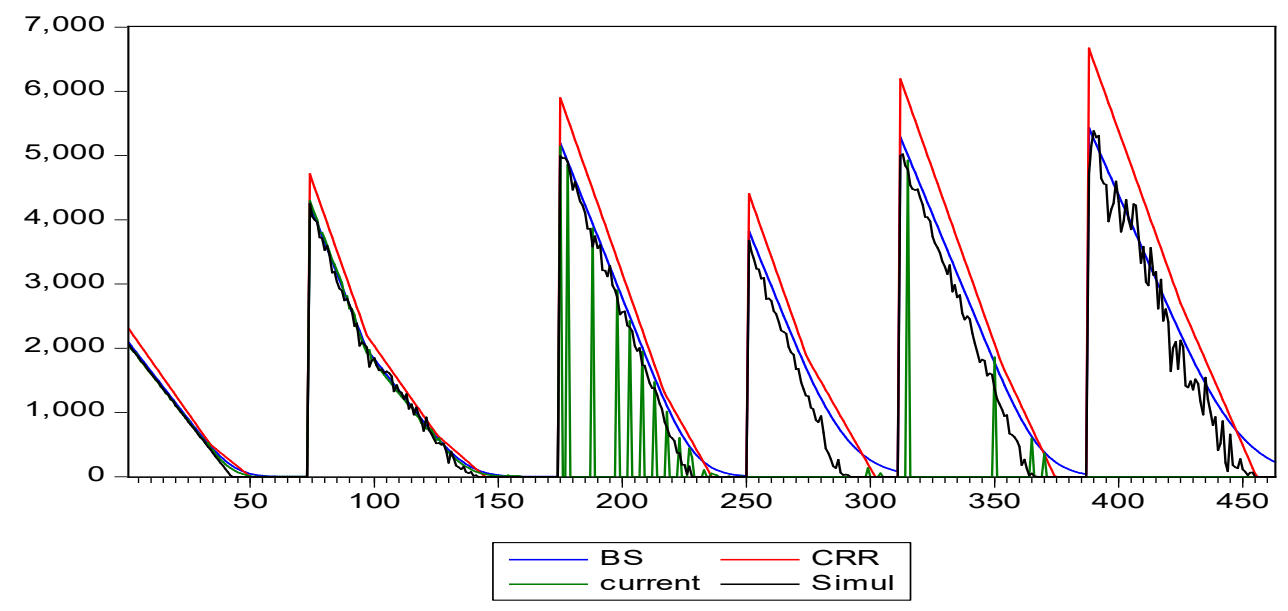

Source: Authors

The Graph 3 shows the convergence of the theoretical prices with the current prices during the period of study, it indicates that the different three models are converging to the current prices in 2014, but in the period of 2015-2016 the current prices are under-valuated comparatively by the different models.

\section{The Greek letters}

We selected three times to maturity for this presentation: (5 months, one year, and 2 years during the period of study (2014-2016).

Table 6.

Descriptive statistics of the Greek letters for three times to maturity

\begin{tabular}{|c|c|c|c|c|c|}
\hline \multicolumn{6}{|c|}{5 months } \\
\hline & Delta & Gamma & Vega & Theta & Rho \\
\hline Mean & 0.731067 & 0.000138 & 6.622110 & -1.317195 & 15.65745 \\
\hline Std. Dev & 0.350482 & 0.000157 & 7.385587 & 0.554785 & 7.200706 \\
\hline Kurtosis & -0.885222 & 0.608855 & 0.628232 & -0.198473 & -0.517308 \\
\hline Skewness & 2.126890 & 1.794396 & 1.823952 & 1.964403 & 2.140762 \\
\hline \multicolumn{6}{|c|}{ One year } \\
\hline & Delta & Gamma & Vega & Theta & Rho \\
\hline Mean & 0.695900 & 0.000157 & 13.59714 & -1.467636 & 26.52644 \\
\hline Std. Dev & 0.296844 & 0.000120 & 9.556276 & 0.393346 & 9.129574 \\
\hline Kurtosis & -0.498458 & -0.174795 & -0.247079 & -0.100875 & -0.745896 \\
\hline Skewness & 1.722060 & 1.504454 & 1.456722 & 1.598148 & 2.197324 \\
\hline \multicolumn{6}{|c|}{2 years } \\
\hline & Delta & Gamma & Vega & Theta & Rho \\
\hline Mean & 0.823922 & 0.000112 & 0.180956 & -0.937720 & 0.777467 \\
\hline Std. Dev & 0.217836 & 0.000119 & 0.177274 & 0.244980 & 0.178663 \\
\hline Kurtosis & -0.960192 & 0.441672 & 0.299442 & 0.338547 & -0.284195 \\
\hline Skewness & 2.465201 & 1.624731 & 1.352943 & 1.898206 & 1.733451 \\
\hline
\end{tabular}

Source: Authors 
This table 6 presents the Five Greek letters or (parameter of sensibility) Delta, Gamma, Vega, Theta and Rho in order to analyze the situation of the call option contact under three different time to maturity 5 months, one year and two years; Delta values range between 0.69 and 0.82 depending on it mean, these high values indicate the possibility of the execution of the contract is higher and the change of $1 \%$ on the stock price leads to the change in the call option value between $69 \%$ and $82 \%$, Gamma value range between 0.000112 and 0.000157 means that the delta is efficient to take the decision of the execution of the contract. Vega value range between 0.180956 and 13.59714 with higher fluctuation $9.55 \%$ comparatively with the other parameters, the Skewness values present the right tail of Vega and a Non-normal distribution, Theta ranges between -0.93 and -1.46 , the last parameter Rho rang between 0.77 and 26.52 Skewness of Theta and Rho shows the right tail and non-normal distribution which is confirmed by the Kurtosis value that is different to zero. The following graphs emphasize the numerical results of the Greek letters, wherein we arrange the values of the parameter of sensibility depending on their indicators; Delta with stock prices, Gamma represents the sensibility of the delta on the stock prices changing, Vega depending on the return volatility, Theta with the time to maturity and Rho arranged depending on the risk-free rate using R program, which gave the next graphs.

Greek Letters graphs for three times to maturity (5 months, one year and 2 years) The graphs 4, 5 and 6 present the Greek letters for three times to maturities.

\section{Graph 4.}

Greek Letters Graphs for 5 months

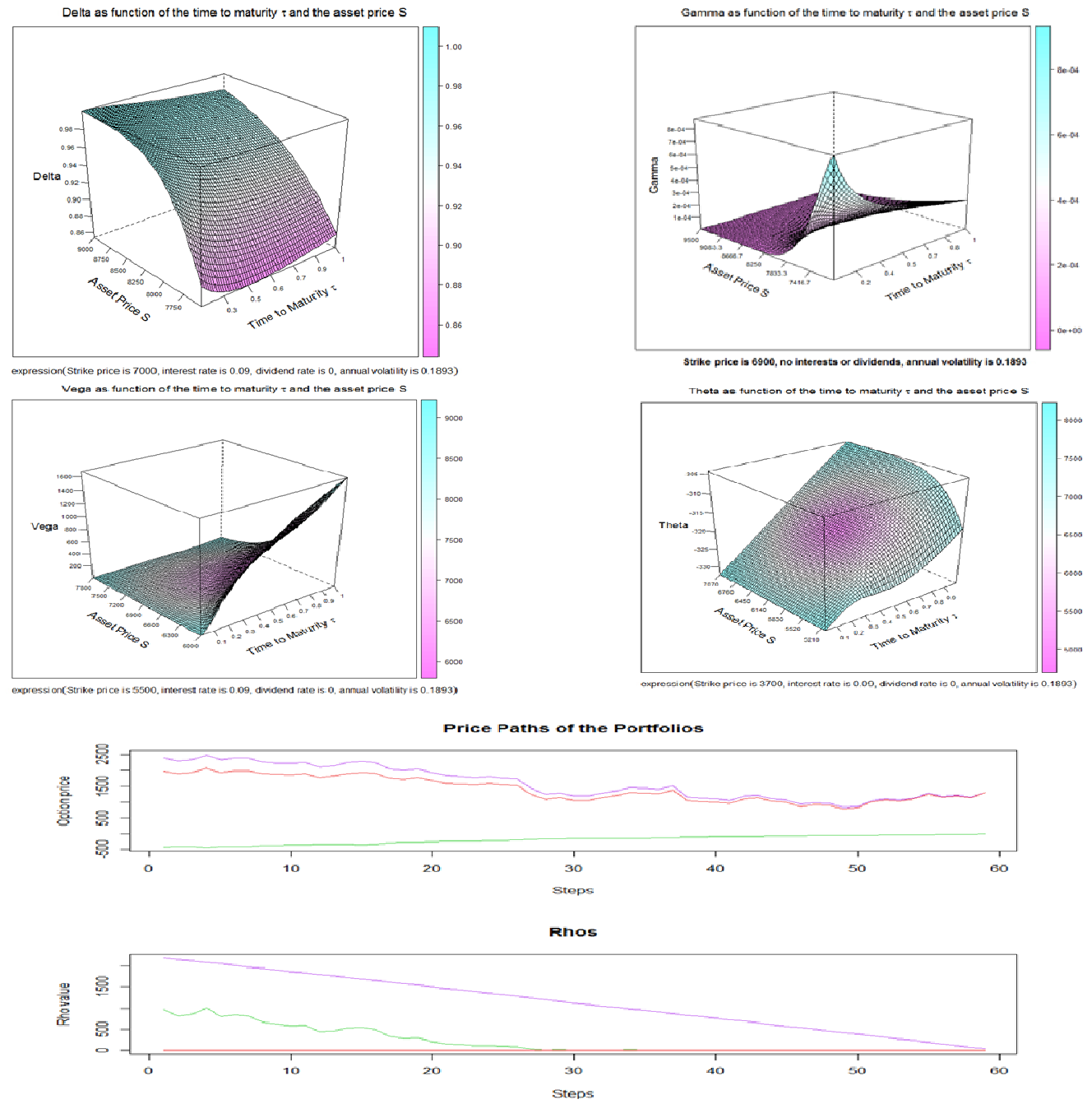

Source: Authors based on Franke J., et al. (2015) codes. 


\section{Graph 5.}

Greek Letters Graphs for one year
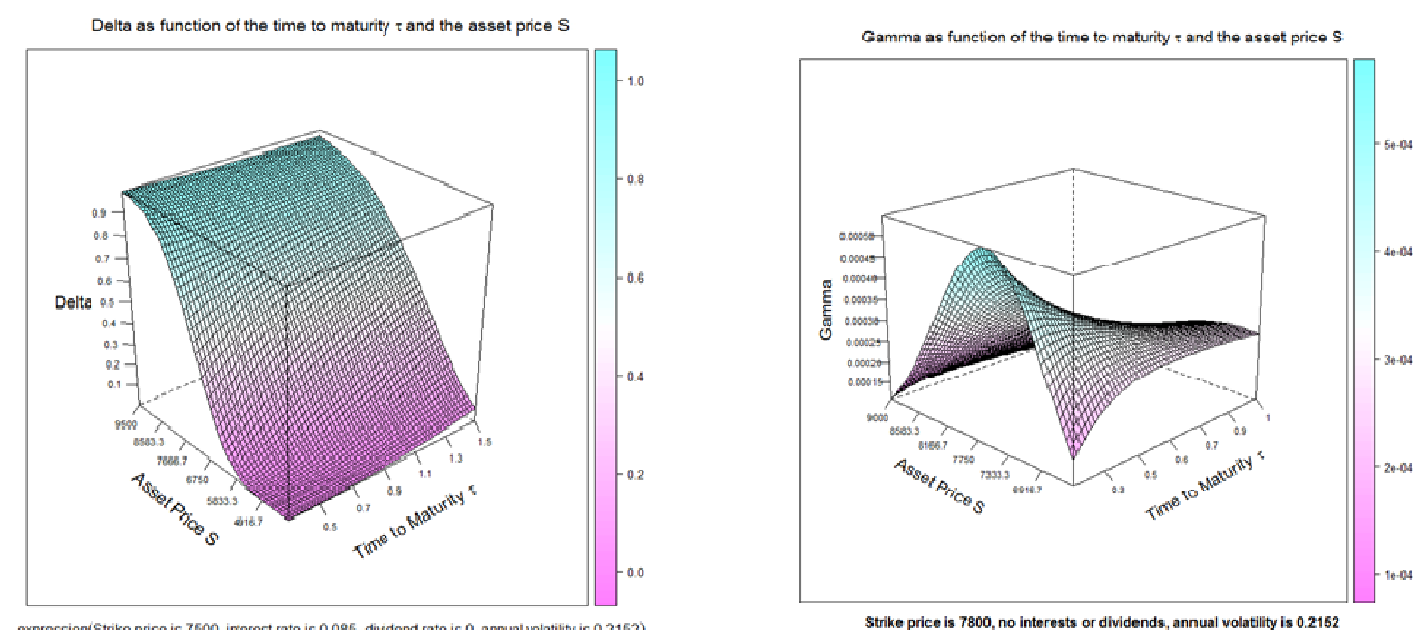

expression(Strike price is 7500 , imerest rate is 0.085 , divdend rate is 0 , annual volatility is 0.2152 )

Strike price is 7800 , no interests or dividends, annual volatility is 0.2152

Vega as function of the time to maturity $z$ and the asset price $S$

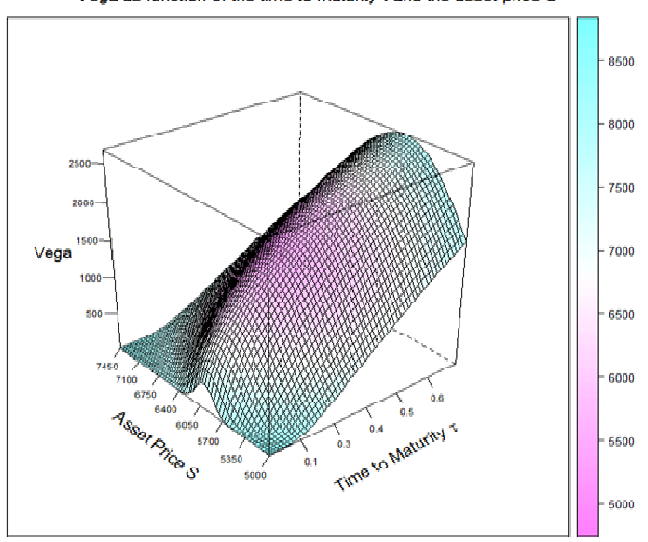

Theta as funetion of the time to maturity $\mathrm{r}$ and the asset price $\mathrm{S}$

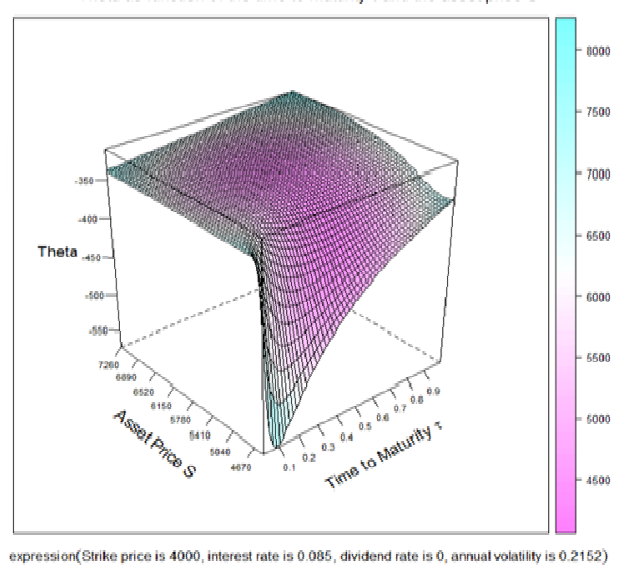

expression(Strike price is 6400 , interest rate is 0.085 , dividend rate is 0 , annual yolatility is 0.2152 )

expression(Strike price is 4000 , interest rate is 0.085 , dividend fate is 0 , annual volatity is 0.2152 )
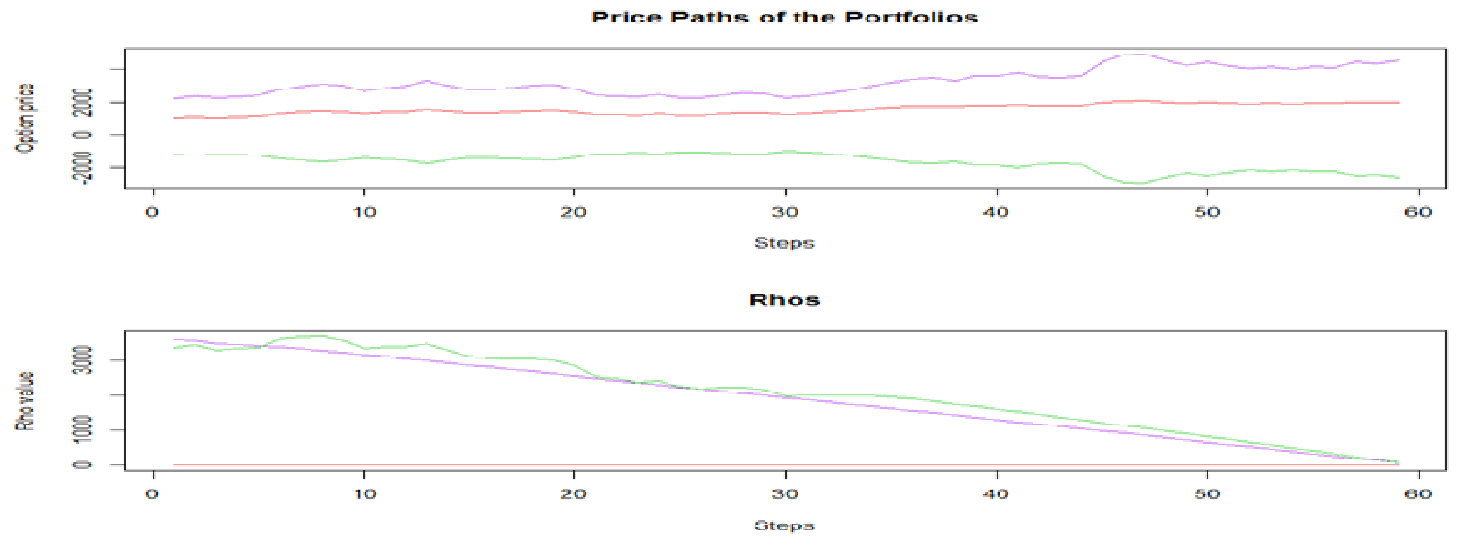

Source: Authors based on Franke J., et al. (2015) codes. 


\section{Graph 6.}

Greek Letters Graphs for two years
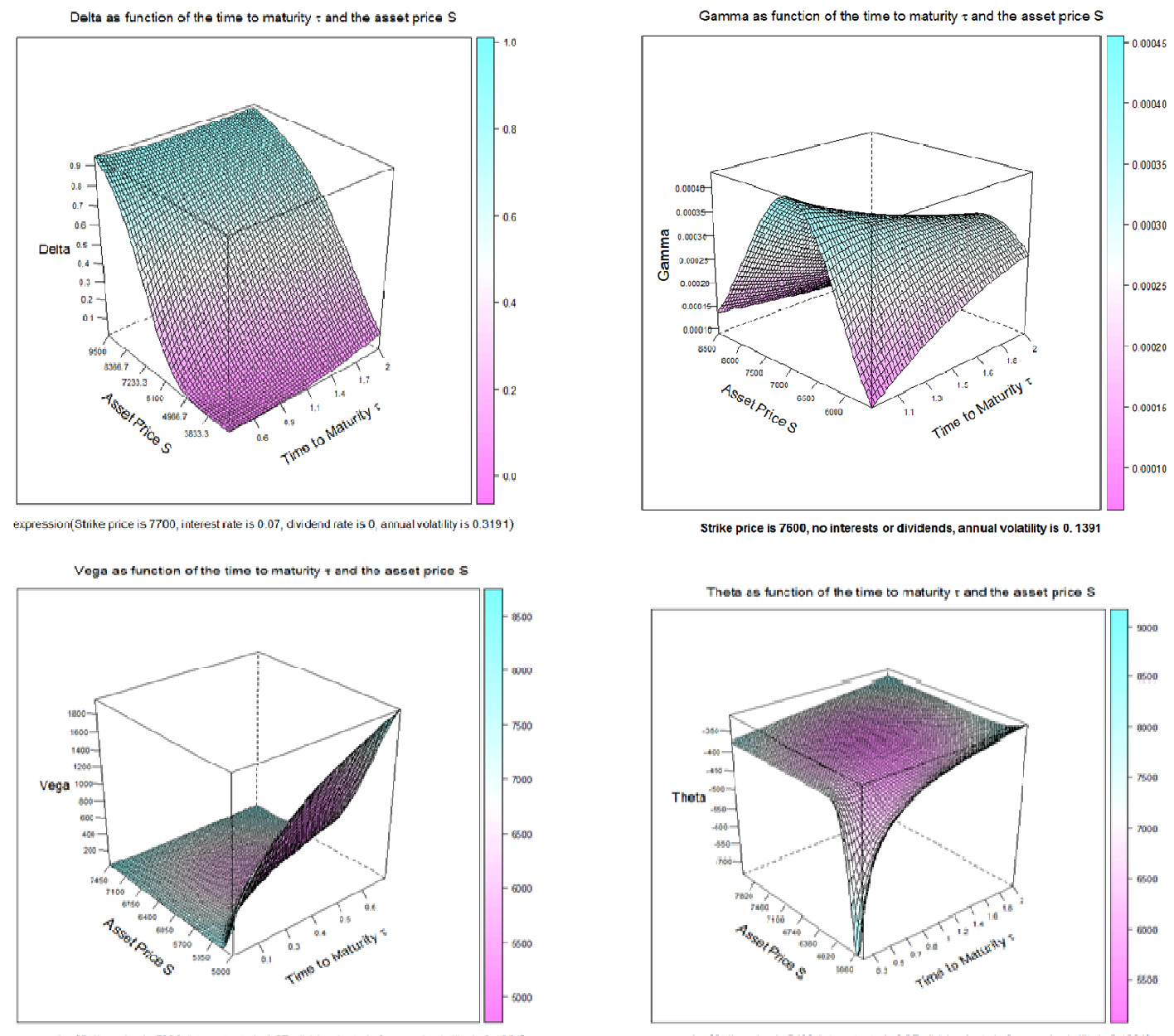

expression( Strike price is 5000 , interes rate is 0.07 , andendrate is 0 , annual volatitity is 0.1391 )

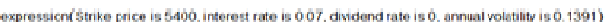

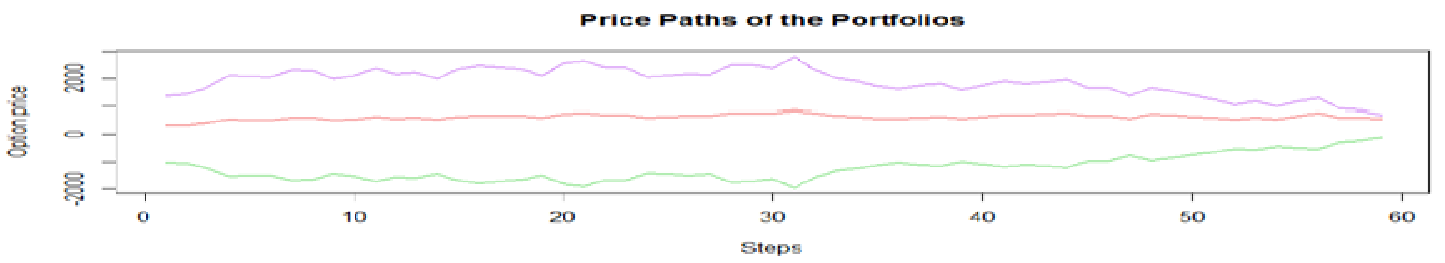

Rhos

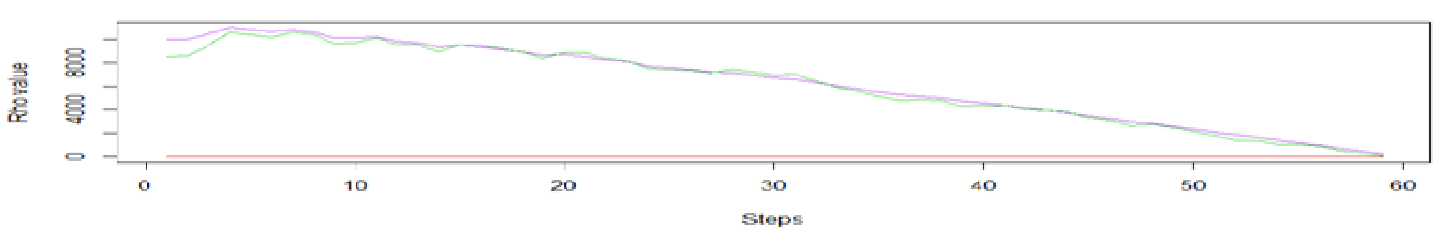

Source: Authors based on Franke J., et al. (2015) codes.

\section{DISCUSSION}

After showing the result of the descriptive statistics of the current and theoretical prices; we can explain the high volatility in the first category by the high sensibility of the options prices to their underlying asset prices and the rest determinants of the option (time to maturity, risk free rate, volatility, ex.) in addition to other factors influencing on option pricing like options market determinants such as the number of option contract traded, open interest rate, and other 
fundamental factors such as the behavior of the traders and theme purposes from the option contracts, which play a big role to predicting the current prices, so we can also explain the high fluctuation in In-the money category by the speculation purposes, which lead to the over-pricing of the theoretical call option prices than the current prices; the macroeconomic variables also have an impact to predicting the current prices like, stock markets, supply of money, the benchmark indexes and other factors. Other finding concludes that the Black-Sholes and the Binomial model are over-priced comparatively the Monte Carlo Simulation Method on three different categories of Moneyness.

The result of the estimation unfold an important fact that the theoretical prices have an impact on the current prices in In-the money category, and the Monte Carlo Simulation model is outperform than the other models when the volatility is lower, the same result was showed in the case of At-the-money when the Monte Carlo Simulation method proved its performance comparatively by the Black-Sholes model, in Out-of-the money only the Binomial model shows a Significance positive relationship with the current prices; as a result we can say the Binomial model is performs when the option I Out-of-the money. When we ignored the Moneyness, the result highlighted that the Black-Sholes model and the Binomial model are outperforming with lower volatility. As a conclusion of this estimation, all of these models are perform when the volatility is not higher.

The descriptive statistics of the Delta shows a high possibility of execution for three times to maturities, it range between 0.69 and 0.82 which mean if the stock price rise with $1 \%$ the call option price will increase by the delta value $(69 \%$ or $82 \%)$, in this case, the holder should buy 6959 or 8239 of stocks to cover his position, but if the stock price decrease the delta value also will decrease, and the holder sell a part of these stocks. Gamma is an indicator to measure the sensibility of the delta to the stock prices, the result shows that Gamma range between 0.00011 and 0.00015 means the efficiency of the Delta to take a decision about the execution and that the holder should own stocks of each number of call option contracts. The sensibility of the call option price to the volatility of stock prices presented by Vega which has a positive relationship between Sigma and the theoretical prices, men when the volatility of the stocks increase by $1 \%$ the option value will increase by the Vega value. while Theta presents the effect of time to maturity on theoretical call option prices, it has a negative relationship with the prices because it takes on account the time value; when the contract is near to the settlement date (In-the-money) the call option price will decrease by Theta value; the last parameter Rho, which relates to strike price and time to maturity, when the risk-free rate increase the call option price will in increase by the value of Rho.

\section{CONCLUSION}

This current paper aims to examine the efficiency of three different options pricing models by comparing the current call prices using the NIFTY50 options Index, with the theoretical prices from the different models which are Monte Carlo Simulation method, Black-Sholes model and the Binomial model, in addition to testing the effect of these models on the market option prices, to predicting the current prices.

Our result highlights that the effect is variable depending on the different type of Moneyness In-the-money, At-the-money and Out-of-the money. The descriptive statistics elucidates all models are overpriced than the current prices in all categories especially in In-the money category because of the high level of fluctuation, that lead to conclude the investors use the option contracts for speculation purposes that confirm the study of Srivastava and Shastri (2018) which it showed a significant difference between the market prices and the theoretical prices. 
We can also explain this high volatility by the augmentation of trading volume and that the expectations of traders are overlooking to the fluctuation on stock prices Srivastava and Shastri (2018).

Moreover, the regression analysis focus to examine the best model to predicting the current prices, when the estimation shows that the Monte Carlo Simulation method is out-perform when the volatility is lower, and the Binomial model is performed in Out-of-the money category, Both of the models Black-Scholes and Binomial proved their efficiency in the case of In the money to determined the which finally both of the Black-Sholes and Binomial models perform when ignoring the Moneyness. Other finding highlights the hedging position that is clear from the Greek Letters delta and gamma for the option's seller because of the high possibility of execution of the contract by the buyer.

\section{References}

Bentouir, N., Bendob, A., Benzemra, M. (2018) Evaluating of call stock options in the Kuwait stock exchange, Roa Iktissadia Review, university of Eloued, Algeria, V08(01)/2018, pp. 155-168. DOI: 10.12816/0052753.

Black, F., Sholes, M. (1973) The pricing of options and corporate liabilities, The Journal of Political Economy, Vol. 81, No. 3, pp. 637-654.

Cox, J. C., Ross, S. A., Rubinstein, M. (1979) Option Pricing: A Simplified Approach, Journal of Financial Economics, Nos SOC-77-18087, pp. 229-263.

Crack, T. F. (2009) Basic Black-Scholes: Option pricing and trading, second edition, United State, ISBN: 0-9700552-4-2.

Čirjevskis, A., Tatevosjans, E. (2015) Empirical Testing of Real Option in the Real Estate Market, Procedia Economics and Finance 24, pp. 50-59. DOI: 10.1016/S2212-5671(15)00611-5.

Flint, E., Maré, E. (2017) Fractional Black-Scholes option pricing, volatility calibration and implied Hurst exponents in South African context, South African Journal of Economic and Management Sciences 20(1), pp. 1-11. a1532. https://doi. org/10.4102/sajems. v20i1.1532.

Franke, J., Härdle, W. K., Hafner, C. M. (2015) Statistics of Financial Markets an Introduction, Fourth Edition, Springer. DOI. 10.1007/978-3-642-16521-4

Girish, G. P., Rastogi, N. (2013) Efficiency of S\&P CNX Nifty Index Option of the National Stock Exchange (NSE), India, using Box Spread Arbitrage Strategy, Gadjah Mada International Journal of Business, Vol. 15, No. 3, pp. 269-285.

Hull, J. C. (2015). Options, Futures, and Other Derivatives (9th ed.), London EC1N 8TS: Pearson.

Katz, J. O., McCormick, D. (2005) Advaced option pricing models. United States: McGraw-Hill.

Miyahara, Y. (2012). Option pricing in incomplete markets, Vol. 3, London: Imperial College Press.

Poon S.-H., Stapleton, R. C. (2005) Asset Pricing in Discrete Time, United States Oxford University Press Inc.

Rebentrost, P., Gupt, B., Bromley, T. R. (2018) Quantum computational finance Monte Carlo pricing of financial derivatives, arXiv [quant-ph], 1805.00109v1, pp. 1-16.

Roman, S. (2004) Introduction to the Mathematics of Finance, New York: Springer-Verlag.

Srivastava, A., Shastri, M. (2018) A study of relevance of Black-Scholes model on option prices of Indian stock market, Internional Jornal Governance and Financial Intermediation 1(1), Vol. 1, No. 1, pp. 82-104.

Swishchuk, A., Shahmoradi, A. (2016) Pricing Crude Oil Options Using Levy Processes (2016) Pricing Crude Oil Options Using Levy Processes, Journal of Energy Markets, pp. 1-14. DOI: 10.21314/JEM.2016.140.

Wang, J. N., Liu, H. C., Chen, L. J. (2017) On forecasting Taiwanese stock index option prices: the role of implied volatility index, International Journal of Economics and Finance 9(9), Vol. 9, No. 9, pp. 133-136. DOI:10.5539/ ijef.v9n9.

Weixuan Xia (2017) Pricing Exotic Power Options with a Brownian-Time-Changed Variance Gamma Process, Communications in Mathematical Finance, Vol. 6, No. 1, Scienpress Ltd, pp. 21-60. 